\title{
Thoc1 inhibits cell growth via induction of cell cycle arrest and apoptosis in lung cancer cells
}

\author{
JIANMEI WAN ${ }^{1 *}$, SHITAO ZOU ${ }^{2 *}$, MENGSHANG HU ${ }^{3}$, RAN ZHU $^{1}$, \\ JIAYING XU ${ }^{1}$, YANG JIAO ${ }^{1}$ and SAIJUN FAN ${ }^{1,4}$ \\ ${ }^{1}$ School of Radiation Medicine and Protection, Medical College, Soochow University, Suzhou, Jiangsu 215123; \\ ${ }^{2}$ Oncology Institute, Wuxi Fourth People's Hospital, Wuxi, Jiangsu 214062; \\ ${ }^{3}$ Department of Nuclear Medicine, The First Affiliated Hospital, Soochow University, Suzhou, Jiangsu 215123; \\ ${ }^{4}$ Tianjin Key Laboratory of Molecular Nuclear Medicine, Institute of Radiation Medicine, \\ Chinese Academy of Medical Sciences and Peking Union Medical College, Tianjin 300192, P.R. China
}

Received October 12, 2013; Accepted February 11, 2014

DOI: $10.3892 / \mathrm{mmr} .2014 .2088$

\begin{abstract}
THO complex 1 (Thoc1) is a human nuclear matrix protein that binds to the retinoblastoma tumor suppressor retinoblastoma protein ( $\mathrm{pRb}$ ). While some studies suggest that Thoc1 has characteristics of a tumor suppressor protein, whether Thoc1 can inhibit lung cancer cell growth is not clear. In the present study, we observed that Thocl is lowly expressed in the lung cancer cell lines SPC-A1 and NCI-H1975. Then, we investigated the potential effects of Thocl on lung cancer cell proliferation, cell cycle and apoptosis after stable transfection of these lines with a Thocl expression vector. We found that overexpression of Thoc1 can inhibit cell proliferation, induce G2/M cell cycle arrest and promote apoptosis. Further investigation indicated that overexpression of Thoc1 is involved in the inhibition of cell cycle-related proteins cyclin A1 and B1 and of pro-apoptotic factors Bax and caspase-3. In vivo experiments showed that tumors overexpressing Thoc1 display a slower growth rate than the control xenografts and show reduced expression of the protein Ki-67, which localized on the nuclear membrane. Taken together, our data show that in lung cancer cells, Thoc1 inhibits cell growth through induction of cell cycle arrest and apoptosis. These results indicate that Thoc1 may be used as a novel therapeutic target for human lung cancer treatment.
\end{abstract}

\section{Introduction}

Lung cancer is the most frequent cancer-related cause of death throughout the world, with a poor $(<15 \%) 5$-year

Correspondence to: Professor Saijun Fan, School of Radiation Medicine and Protection, Soochow University Medical College, 199 Ren'ai Road, Suzhou, Jiangsu 215123, P.R. China

E-mail: fansaijun2013@126.com

*Contributed equally

Key words: Thoc1, nuclear matrix proteins, proliferation, apoptosis, Ki-67 survival rate (1). More effective approaches to the treatment and prevention of lung carcinoma depend on a better understanding of the cellular and molecular mechanisms that control lung tumor growth. During carcinogenesis, alterations of the nuclear structure usually manifest as deformations of the nuclear matrix architecture (2-4). Changes in nuclear structure, which are largely determined by the nuclear matrix, have long been recognized to correlate with tumor growth and progression, prompting their use as biomarkers for the diagnosis of cancer (5).

The nuclear matrix consists of the nuclear lamins, RNA, and a fibrogranular network of proteins that include $>200$ nuclear matrix proteins (NMPs) (6). Numerous NMPs are involved in important cellular functions, including gene transcription, steroid hormone binding, and RNA processing. Functional changes in these proteins have been associated with carcinogenesis (7-9), and many NMPs have been identified as unique 'fingerprint' markers for cancers of the colon (2), bladder (10), kidney (11), prostate (12) and breast (13). For example, Partin et al found that the level of the NMP PC-1 is specifically elevated in prostatic cancer tissue compared to benign prostatic hyperplasia and normal prostatic tissue (14). Getzenberg et al found that BLCA-4 expression was detectable before tumors were identified, highlighting the diagnostic significance of this NMP in transitional cell carcinoma (10).

The human protein THO complex 1 (Thoc1), also called $\mathrm{hHpr} 1 / \mathrm{p} 84$, was originally identified as a nuclear matrix component protein that binds to the tumor suppressor retinoblastoma protein (pRb) (5). High levels of Thoc1, observed in breast and lung cancer cells, have been associated with tumor size and aggressiveness $(15,16)$. Thoc1 is expressed in most tissues throughout the cell cycle, except for the G0 phase (17). Overexpression of Thoc1 can induce p53-independent apoptosis that is inhibited by binding of Thoc1 to pRb $(18,19)$. It was additionally reported that depletion of Thoc1 sensitizes cancer cells to the cytotoxic effects of DNA damage (20).

This study was undertaken to evaluate the effect of Thoc1 on lung cancer cell proliferation, cell cycle and apoptosis by creating stable transfectants and evaluating their in vitro growth potential. Furthermore, we examined whether the 
effects of Thoc1 may be also observed in vivo, using nude mice. We show, for the first time to the best of our knowledge, that overexpression of Thocl inhibits lung cancer cell growth.

\section{Materials and methods}

Cell cultures. Human lung cancer cell lines SPC-A1 and NCI-H1975 were obtained from the Shanghai Cell Bank (Shanghai, China). Cells were cultured in RPMI-1640 medium (Gibco-BRL, Carlsbad, CA, USA) containing 10\% fetal bovine serum in a humidified atmosphere with $5 \% \mathrm{CO}_{2}$ at $37^{\circ} \mathrm{C}$.

Generation of stable cell lines. To generate stable cell lines overexpressing Thoc1, the cDNA encoding the human full-length Thocl gene was amplified by PCR using the following primers: forward, 5'-TTCCTCGAGATGTCTCCGACGCCGC-3' and reverse, 5'-CCGGATCCACTATTTGTCTCATTGTC-3'. Next, the full-length cDNA was cloned into the linearized plasmid vector pcDNA3 (Clontech Laboratories, Inc., Mountain View, CA, USA) between the XhoI and BamHI restriction sites. The resulting expression vector pcDNA3/Thoc1 and the control empty vector pcDNA3 were transfected in SPC-A1 and NCI-H1975 cells using Lipofectamine 2000 (Invitrogen Life Technologies, Carlsbad, CA, USA). Stable clones were selected in medium containing 800 or $500 \mu \mathrm{g} / \mathrm{ml} \mathrm{G} 418$ (Sigma-Aldrich, St. Louis, MO, USA). Individual clones were isolated and grown for further characterization.

Western blot analysis. Cells were lysed with sodium dodecyl sulfate (SDS) buffer ( $80 \mathrm{mM}$ Tris-HCl, $2 \%$ SDS, $300 \mathrm{mM}$ $\mathrm{NaCl}$ and 1.6 mM EDTA). Proteins were separated using $10 \%$ SDS-polyacrylamide gel electrophoresis, transferred onto a polyvinylidene difluoride membrane and blocked with $5 \%$ skimmed milk. Membranes were next incubated with antibodies targeting $\beta$-actin, Thoc1 (Abcam Inc., Cambridge, MA, USA), cyclin A1, cyclin B1, cyclin D1, Bax (Cell Signaling Technology, Inc., Danvers, MA, USA), Bcl-2 (EMD Millipore Corp., Billerica, MA, USA), caspase-3 (Abcam Inc.) and then incubated with HRP-conjugated anti-mouse or -rabbit IgG antibodies (Cell Signaling Technology, Inc.). Protein bands were visualized using an enhanced chemiluminescence (ECL) solution (EMD Millipore Corp.).

Quantitative PCR ( $q P C R)$. Total RNA was extracted using TRIzol (Gibco-BRL, Grand Island, NY, USA) and treated with RNase-free DNase I to remove genomic DNA (Roche Diagnostics, Indianapolis, IN, USA). cDNA was prepared from $1 \mu \mathrm{g}$ of total RNA using M-MLV reverse transcriptase (MBI; Fermentas, Waltham, MA, USA). Amplifications were performed on an ABI Prism 7300 PCR system (Applied Biosystems, Foster City, CA, USA) and reactions were prepared using the SYBR ${ }^{\circledast}$ Premix Ex Taq ${ }^{\mathrm{TM}}$ kit (Takara Bio, Dalian, China). The sequences of the primers for amplification of the human genes Thoc1 and $\beta$-actin (considered as housekeeping) were as follows: Thoc1 forward, 5'-CTGTGGACGGATTCAGCTCT-3' and reverse, 5'-AG AGCACGTTGTTGGAGCTT-3'; $\beta$-actin forward, 5'-AGC GAGCATCCCCCAAAGTT-3' and reverse, 5'-GG GCACGAAGGCTCATCATT-3'. Standard curves were generated for each gene. The amplification was $90-110 \%$ efficient. Relative quantification of gene expression was determined by comparison of threshold cycle values. The expression level of all genes was normalized to that of $\beta$-actin.

Cell proliferation assay. Cell proliferation was measured with the MTT assay. Cells $\left(5 \times 10^{3}\right)$ were plated in 24-well plates and $1 \mathrm{ml}$ of culture medium was added to each well. The cells were incubated at $37^{\circ} \mathrm{C}$ for $1,2,3,4,5,6$ or 7 days (d), and incubated with $500 \mu \mathrm{l}$ of MTT solution (1 g/l; Sigma-Aldrich) for an additional $2 \mathrm{~h}$. The reaction was stopped by the addition of $500 \mu 1$ dimethylsulfoxide (Sigma-Aldrich) and the absorbance of samples was then measured at $570 \mathrm{~nm}$. A growth curve was plotted for each sample as the absorbance vs. time. Three independent experiments were performed, and the results were used for calculating the relative growth rate \pm SD.

Flow cytometry analysis of cell cycle and apoptosis. For cell cycle analysis, after $24 \mathrm{~h}$ of culture, cells were collected and digested with trypsin, and fixed overnight with $75 \%$ ice-cold ethanol at $4^{\circ} \mathrm{C}$. Cells $\left(1 \times 10^{6}\right)$ were centrifuged at $106 \mathrm{x}$ for $5 \mathrm{~min}$, and the cells were resuspended and incubated in $500 \mu \mathrm{l}$ propidium iodide (50 $\mu \mathrm{g} / \mathrm{ml}$; Sigma-Aldrich) for $30 \mathrm{~min}$ in the dark before analysis. The cell cycle profiles were assessed by measurements, at $488 \mathrm{~nm}$, on a FC500 flow cytometer (Beckman Coulter, Brea, CA, USA), and the data were analyzed using the Multicycle software (Phoenix Flow Systems, Inc., San Diego, CA, USA). For the analysis of apoptosis, cells were collected and digested with trypsin, processed as described in the Annexin V-FITC Apoptosis Detection kit (BD Biosciences, San Diego, CA, USA) and analyzed on a FC500 flow cytometer.

In vivo studies. Four-week-old female nude specific pathogen-free (SPF) BALB/c mice were obtained from the Laboratory Animal Center of Soochow University, and kept in a room at constant temperature $\left(23 \pm 2^{\circ} \mathrm{C}\right)$ and humidity $(50-70 \%)$ with a $12 \mathrm{~h}$ light-dark cycle. SPC-A1 cells and their transfectants were trypsinized and harvested, washed with phosphate-buffered saline (PBS) and resuspended in $0.2 \mathrm{ml}$ PBS $\left(1 \times 10^{7}\right.$ cells $\left./ 0.2 \mathrm{ml}\right)$. They were subcutaneously injected into the oxter of the nude mice. Each study group comprised six nude mice. Every three or four days, the tumor diameter was measured, and the volume was calculated according to the formula $\mathrm{V}=\left(\mathrm{W}^{2} \mathrm{x} \mathrm{L}\right) / 2$, where $\mathrm{W}$ denotes tumor width and $\mathrm{L}$ tumor length. The growth curve of each tumor was plotted and the tumor growth ratio was calculated. Five weeks after injection of the cells, the mice were sacrificed, and tumors were collected for histological analysis. The animal treatment protocol used in this study was approved by the Institutional Animal Care and Use Committee of Soochow University (Suzhou, China).

Immunofluorescence microscopy analysis. Tumors were analyzed using immunofluorescence analysis. The tumor xenografts were removed and fixed in $10 \%$ phosphate-buffered formaldehyde at room temperature for $48 \mathrm{~h}$, embedded in paraffin, and sectioned at $5 \mu \mathrm{m}$. The sections were deparaffinized, rehydrated, antigens were retrieved in Tris/EDTA buffer at $100^{\circ} \mathrm{C}$ for $15 \mathrm{~min}$, and left in the buffer for $10 \mathrm{~min}$ after boiling. Following a rinse in distilled water and PBS, the sections were treated with $0.03 \%$ hydrogen peroxide for $5 \mathrm{~min}$ 
to block endogenous peroxidase activity, then incubated with mouse anti-human anti-Thoc1 (1:100; Abcam Inc.) and -Ki-67 antibody (1:100; Cell Signaling Technology, Inc.) overnight at $4^{\circ} \mathrm{C}$, Following a rinse in PBS, the sections were incubated with Alexa Fluor 488/633-conjugated anti-rabbit antibody (1:1,000; Cell Signaling Technology, Inc.) for $30 \mathrm{~min}$ at room temperature. Next, they were rinsed in PBS, and the cell nuclei were stained with 4',6-diamidino-2-phenylindole (DAPI) for $5 \mathrm{~min}$ at room temperature. The sections were finally prepared for confocal microscopy, and images were recorded and analyzed with the TCS SP2 software (Leica, Wetzlar, Germany).

Statistical analysis. Each experiment was repeated 3 times. Results are expressed as mean \pm SD. A P-value $<0.05$ was considered to indicate statistically significant differences. Statistical analyses were performed using the SPSS 17.0 software (IBM, Armonk, NY, USA).

\section{Results}

Expression of Thoc1 in lung breast cancer cell lines and generation of stable cell lines. To investigate the potential role of Thoc1 in human lung cancer, we first detected the expression of Thoc1 in a panel of human lung cancer cell lines. The mRNA level of Thoc1 in these cell lines was determined by qPCR. As shown in Fig. 1A, the lowest Thoc1 mRNA level was observed in SPC-A1 and NCI-H1975 cells. To further explore the role of Thoc1 in lung cancer cells, SPC-A1 and NCI-H1975 cells were transfected with recombinant vector expressing Thoc1 (pcDNA3/Thoc1) or a control empty vector (pcDNA3/Neo). G418-resistant mix clones were selected for further experiments. The Thoc1 mRNA and protein levels in SPC-A1 and NCI-H1975 cells were measured by qPCR (Fig. 1B) and western blot analysis (Fig. 1C), respectively. When compared to control cells, Thocl expression was significantly increased in the cells transfected with the pcDNA3/Thoc1 sense vector (SPC-A1/Thoc1 and NCI-H1975/Thoc1 cells).

Overexpression of Thoc1 inhibits lung cancer cell proliferation. First, we addressed the question whether Thoc1 is involved in regulation of lung cancer cell proliferation, using the MTT assay to determine cell proliferation. The untransfected SPC-A1 or NCI-H1975 cells, the control cells (transfected with empty vector), as well as the SPC-A1/Thoc1 or NCI-H1975/Thoc1 cells were grown in culture for 7 days. The proliferative ability of SPC-A1/Thoc1 and NCI-H1975/Thoc1 cells decreased compared to untransfected and control cells, in a time-dependent manner (Fig. 2).

Overexpression of Thoc1 induces G2/M cell cycle arrest in lung cancer cell lines. Because overexpression of Thoc1 led to inhibition of lung cancer cell proliferation, we asked whether it can also influence progression of the cell cycle. To address this question, we conducted a cell cycle analysis and assessed the expression of proteins related to the cell cycle before and after transfection with the Thoc1 expression vector. Notably, increased amounts of cells at the G2/M phase were observed in SPC-A1/Thoc1 and NCI-H1975/Thoc1 cells compared to the controls and the untransfected cells. In addition, a shift at the G1 phase was detected (Fig. 3A).
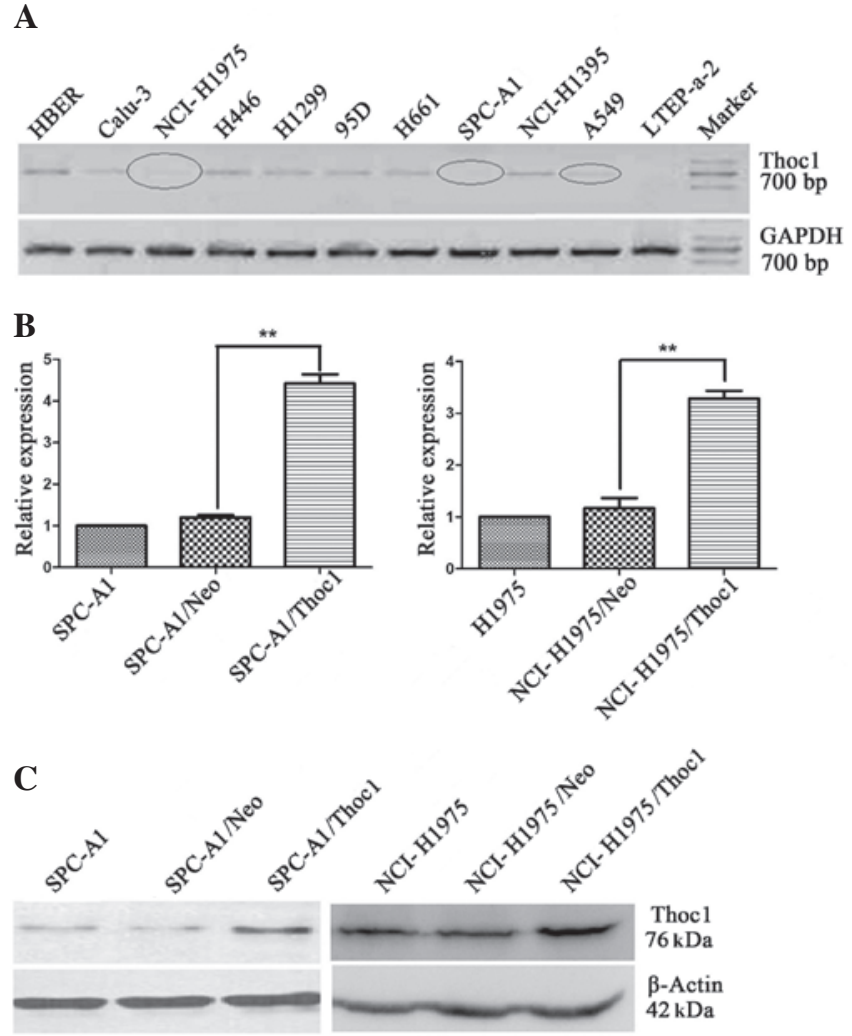

Figure 1. Expression of Thoc1 in lung cancer cell lines and generation of stable cell lines. Thoc1 mRNA was detected by quantitative polymerase chain reaction in (A) a panel of breast cancer cell lines, as indicated, and (B) SPC-A1 and NCI-H1975 cells transfected with pcDNA3/Neo or pcDNA3/Thoc1. The GAPDH level served as the loading control in all experiments. ${ }^{* *} \mathrm{P}<0.01$. (C) Protein expression of Thoc1 was analyzed by western blot analysis. The $\beta$-actin level served as the loading control. Neo, empty vector

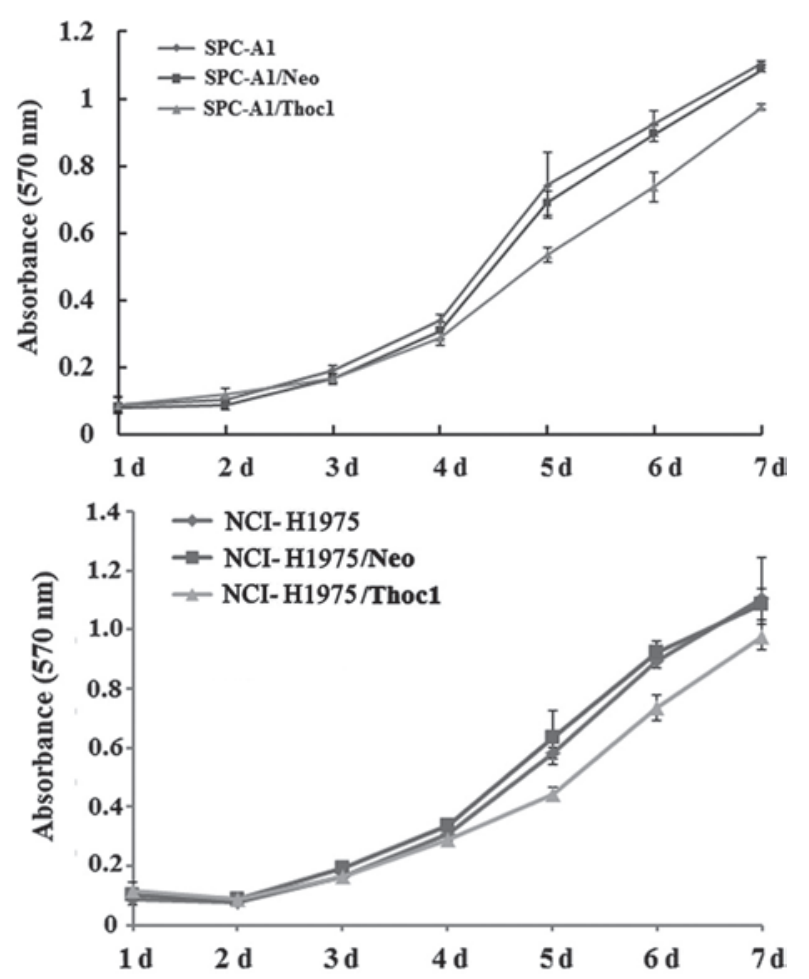

Figure 2. Overexpression of Thoc1 inhibits lung cancer cell proliferation. SPC-A1, NCI-H1975 cells and their transfectants were cultured in 24-well plates at a density of $5 \times 10^{3} /$ well for $1,2,3,4,5,6$ and 7 days (d). Cell growth was assessed by the MTT assay. Neo, empty vector. 
A
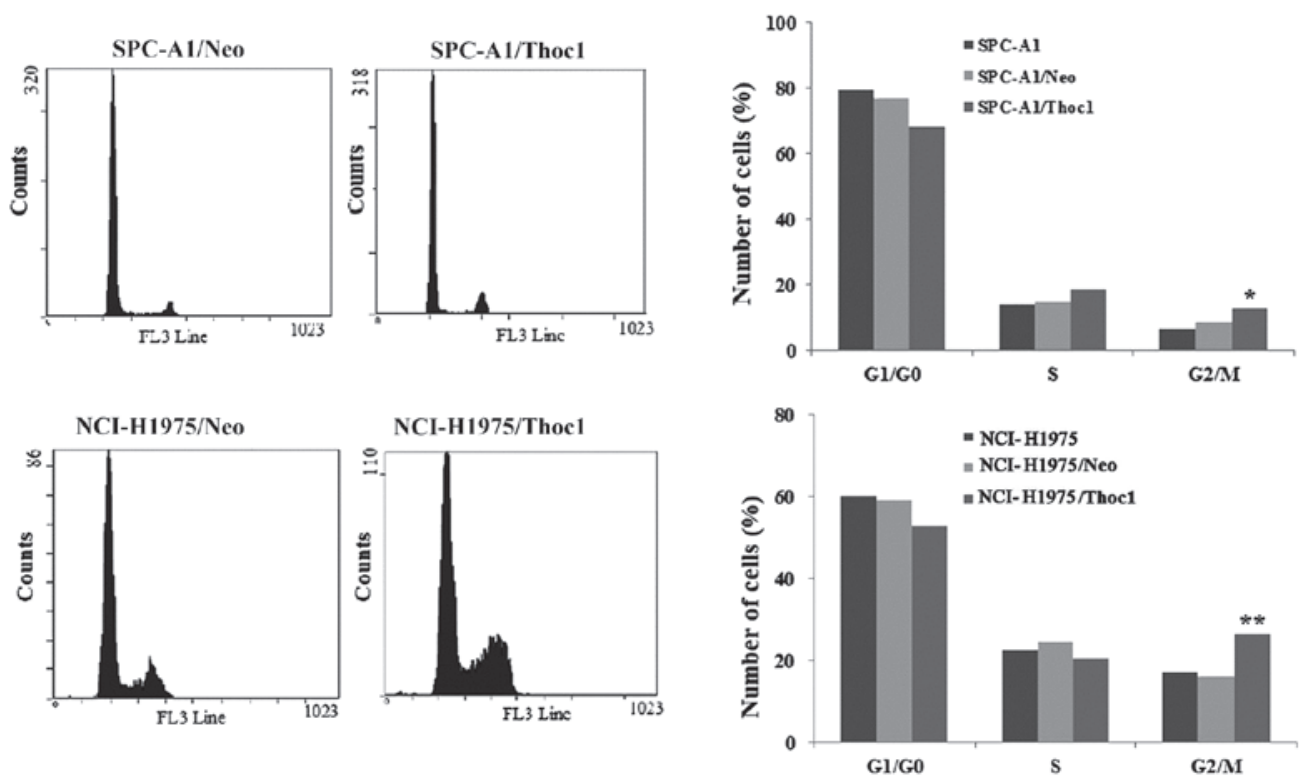

B

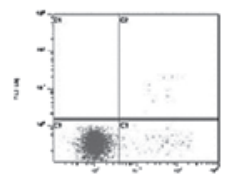

SPC-Äl

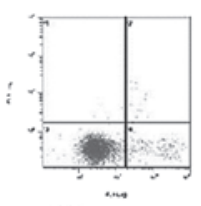

NCI-H1975

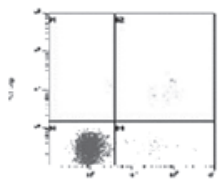

SPC-Ä/Neo

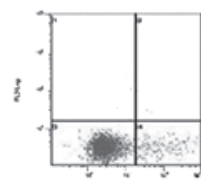

NCI-H1975/Neo

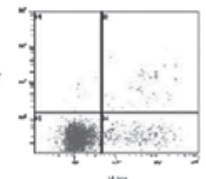

SPC-A1/Thocl

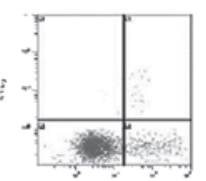

NCI-H1975/Thoel

C

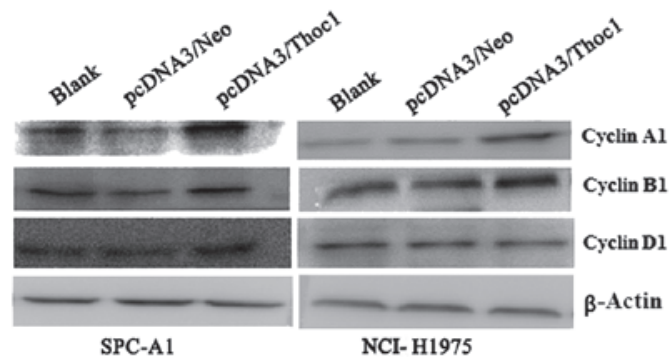

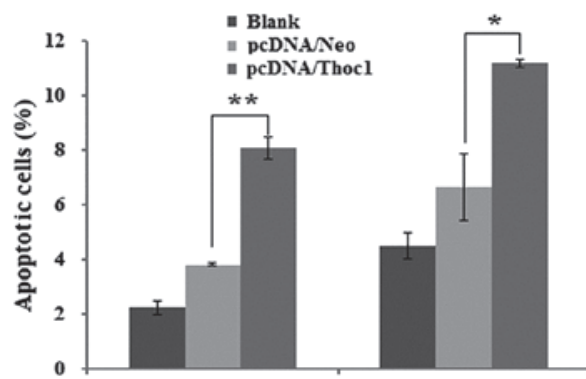

SPC-A1

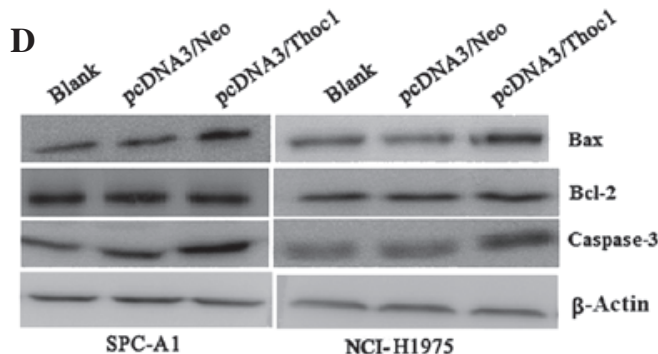

Figure 3. Overexpression of Thoc1 induces G2/M cell cycle arrest and promotes cell apoptosis in lung cancer cells. (A) After 24 h of culture, SPC-A1, NCI-H1975 cells and their transfectants were collected to assess cell cycle distribution using flow cytometry. ${ }^{*} \mathrm{P}<0.05$. (B) Percentage of apoptotic cells in the SPC-A1, NCI-H1975 and their transfectant lines, as detected by the Annexin V-fluorsecein isothiocyanate assay. ${ }^{* *} \mathrm{P}<0.01$. (C and D) Western blot analysis showing cyclin A1, B1 and D1, Bcl-2, Bax and caspase-3 protein levels in SPC-A1 and NCI-H1975 cells transfected with either the control vector pcDNA3/Neo or pcDNA3/Thoc1 and in the corresponding untransfected cells (blank). The $\beta$-actin level served as the loading control. Bcl-2, B-cell lymphoma 2; Bax, Bcl-2-associated X.

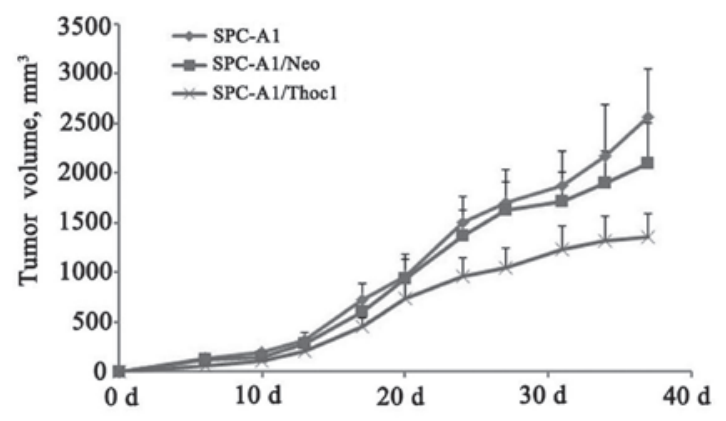

Figure 4. Effect of Thoc1 overexpression in vivo, assessed by growth curves of lung cancer SPC-A1 xenografts in nude mice. Following injection of $1 \times 10^{7}$ SPC-A1/Thoc1 cells, control cells (SPC-A1/Neo) or untransfected (SPC-A1) cells, the tumor diameter was measured every three or four days.
To further characterize the molecular mechanism underlying the $\mathrm{G} 2 / \mathrm{M}$ cell cycle arrest, we studied the expression of the main proteins related to the cell cycle before and after transfection with the Thoc1 expression vector. As shown in Fig. 3C, overexpression of Thoc1 led to a significant increase in the cyclin B1 and A1 expression levels, which correlates with the increase in the population of G2/M-arrested cells.

Overexpression of Thoc1 promotes cell apoptosis in lung cancer cell lines and changes in Bcl-2, Bax and caspase-3 expression. The extent of apoptosis was investigated by estimating the number of cells stained with Annexin V, which is a marker of early-stage apoptosis. In this assay, the percentage of apoptotic 
A
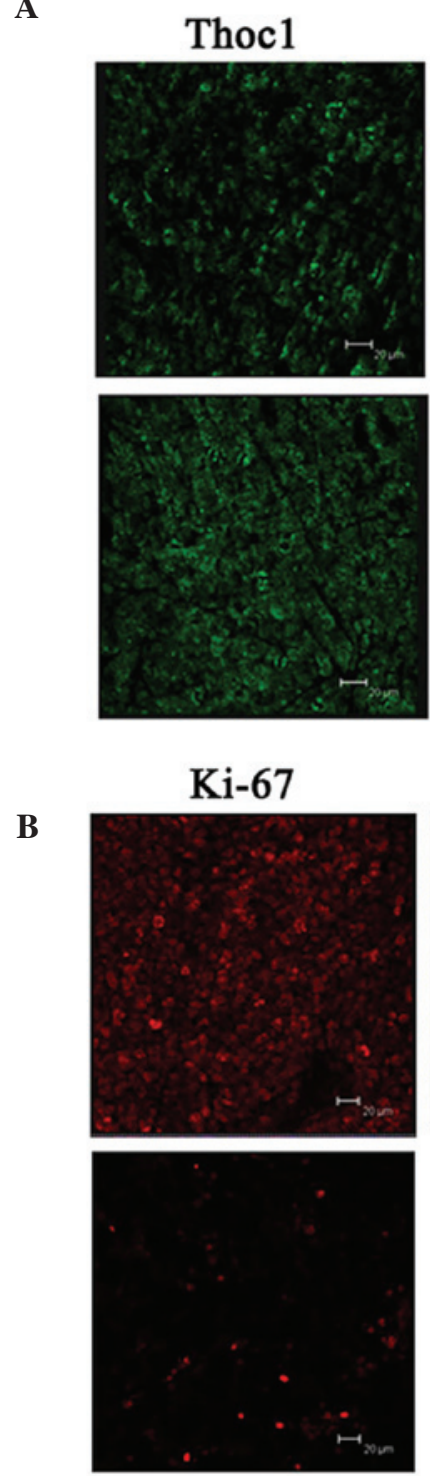

DAPI
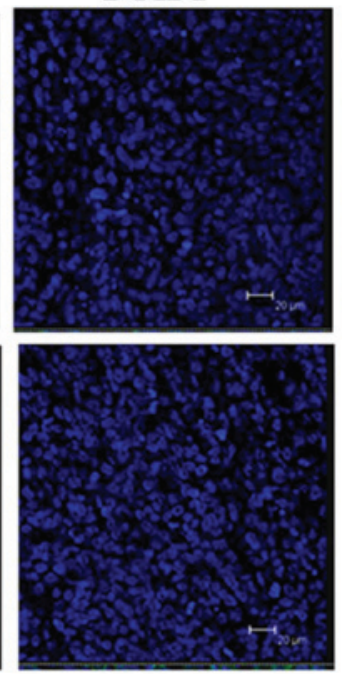

DAPI
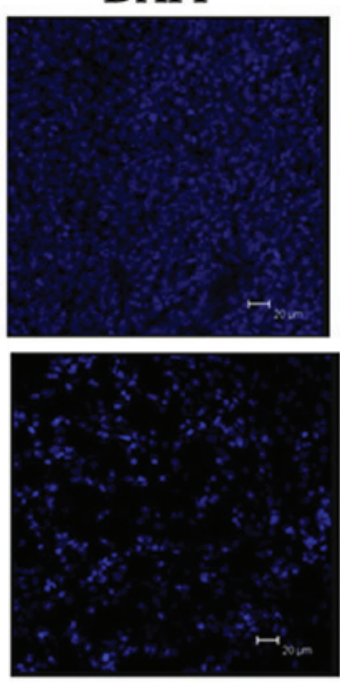

Merge

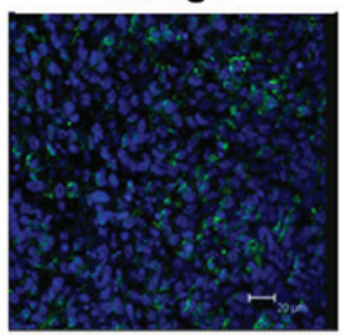

SPC-A1/Neo

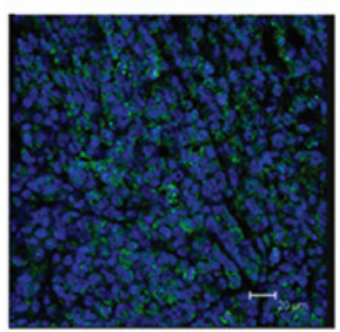

\section{SPC-A1/Thoc1}

SPC-A1/Neo
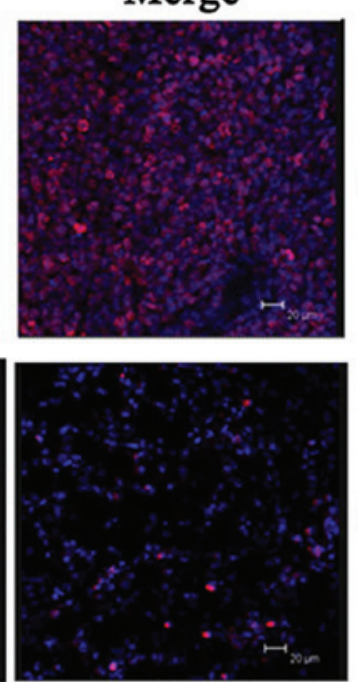

SPC-A1/Thoc1

Figure 5. Immunofluorescence microscopy analysis. (A) Thoc1 expression appeared higher in the SPC-A1/Thoc1 cell tumors, and the protein localized on the nuclear membrane and appeared to be concentrated in localized spots outside the nucleus. (B) Ki-67 appeared less expressed in the SPC-A-1/Thoc1 cell tumors and localized on the nuclear membrane. DAPI, 4',6-diamidino-2-phenylindole; merge, superposition of the protein- and the DAPI- stained fields.

cells was higher for the SPC-A1/Thoc1 and NCI-H1975/Thoc1 cells compared to control or untransfected cells (Fig. 3B). To further characterize the molecular mechanism underlying the induction of cell apoptosis, we detected the expression levels of anti-apoptotic factor Bcl-2 and pro-apoptotic factors Bax and caspase-3 using western blot analysis. As shown in Fig. 3D, overexpression of Thoc1 increased the expression of the pro-apoptotic proteins Bax and caspase- 3 and did not affect Bcl-2 expression in a significant manner in SPC-A1/Thoc1 and NCI-H1975/Thoc1 cells. These results indicated that the promotion of cell apoptosis by Thoc1 is most likely mediated by Bcl-2, Bax and caspase-3 proteins in lung cancer cells.

Overexpression of Thoc1 inhibits xenograft formation and growth in vivo. In vitro experiments with the SPC-A1 and NCI-H1975 cells showed that the overexpression of Thoc1 can induce G2/M cell cycle arrest and apoptosis, and inhibit cell growth. Hence, we examined whether this effect could be also observed in vivo. The transfected (pcDNA3/Thoc1 or negative control pcDNA3/Neo) and untransfected SPC-A1 cells were subcutaneously injected into nude mice $(n=6$ per group). After five weeks of growth, the tumor masses obtained from the SPC-A1/Thoc1 cell xenografts were markedly smaller than those from the control mice (Fig. 4, P<0.05). Immunofluorescence staining showed that Thocl expression was higher in the SPC-A1/Thoc1 cell tumors (Fig. 5A), and that the protein localized on the nuclear membrane and appeared to be concentrated in localized spots without the nucleus. By contrast, Ki-67 appeared less expressed in the SPC-A1/Thoc1 cell tumors (Fig. 5B) and localized on the nuclear membrane. These results strongly supported the in vitro observations and indicated that Thoc1 might play an important role in lung cancer cell growth.

\section{Discussion}

Thoc1 has been identified as a human nuclear matrix protein for more than a decade (5). In a previous study, Thoc1 expression 
tended to associate with poor survival in subgroups of patients who were at an early tumor stage, had tumors of squamous cell type, or had a family history of lung cancer (16). The exact role of Thocl in lung cancer has however not been elucidated. In this study, we investigated the role of Thocl in growth of lung cancer cells. The Thocl expression vector induced overexpression of the Thoc1 mRNA and protein in lung cancer cells, which further showed reduced proliferation, G2/M cell cycle phase arrest and apoptosis.Nude mice injected with Thoc1-overexpressing cells also showed reduced xenograft formation and in vivo growth. Our findings show that Thocl plays a role in lung cancer cell growth. Furthermore, in an attempt to elucidate the mechanisms underlying the observed effects, we obtained evidence that Thocl may regulate key genes of cell cycle and apoptosis.

Cell cycle deregulation resulting in uncontrolled cell proliferation is one of the most frequent alterations that occur during tumor development. The $\mathrm{G} 2 / \mathrm{M}$ checkpoint regulators cyclin A1 and B1 are markers of $\mathrm{G} 2 / \mathrm{M}$ cell cycle arrest induced by DNA damage. The expression level of cyclin A1 and $\mathrm{B} 1$ is minimal at the initiation of $\mathrm{S}$ phase and peaks at the $\mathrm{G} 2 / \mathrm{M}$ checkpoint $(21,22)$. In this study, we found that overexpression of Thocl can affect cell cycle distribution in the lung cancer cell lines SPC-A1 and NCI-1975, induce G2/M phase arrest and reduce the population of cells at the G1/G0 phase. Furthermore, we found that cyclin A1 and B1 protein levels increased in response to Thoc1 overexpression in the lung cancer cell lines SPC-A1 and NCI-H1975, indicating that this increase might cause the increase in the population of G2/M-arrested cells. The cyclin D1 protein level did not significantly change in response to Thocl overexpression.

Apoptosis has been considered the major form of cancer cell death, and occurs through two pathways: The extrinsic or cytoplasmic pathway, and the intrinsic or mitochondrial one. Bcl-2 family proteins are in part controlling the intrinsic pathway $(23,24)$. This family is composed of various pro- and anti-apoptotic proteins that heterodimerize and modulate each other's function. Thus, the relative concentration of each $\mathrm{Bcl}-2$ family member is thought to determine whether programmed cell death will occur. The ratio of anti-apoptotic Bcl-2 to pro-apoptotic Bax is a critical determinant of apoptosis, as Bcl-2 heterodimerizes with Bax, blocking apoptosis (25). In this study, we demonstrated that overexpression of Thoc1 induces lung cancer cell apoptosis, accompanied by a rise in Bax and caspase- 3 levels, while no significant changes in the level of Bcl-2 were observed. These results indicate that the inhibitory effect of Thoc1 on cell apoptosis most likely involves a reduction in the $\mathrm{Bcl}-2 / \mathrm{Bax}$ ratio. Bax upregulation was reported to result in loss of the mitochondrial transmembrane potential and cytochrome $\mathrm{C}$ release, followed by activation of the caspase cascade (26).

An important finding of the present study is that Thoc1 inhibited lung cancer cell growth in vitro and in vivo, as confirmed by our animal model. The growth rate of established Thoc1-overexpressing xenografts was slower compared to the empty vector control group. The Ki-67 protein is a marker of proliferation, and is strongly linked to cell cycle control. During mitosis, phosphorylation and dephosphorylation of Ki-67 occur at the breakdown and the reorganization of the nucleus, two hallmark events of the cell cycle $(27,28)$. Molecular functions proposed for Ki-67 include organization and maintenance of the DNA architecture and synthesis of ribosomes during mitosis $(29,30)$. There is a positive correlation between Ki-67 protein expression, cell proliferation rate, and the active phase of the cell cycle in invasive breast carcinoma $(31,32)$. In this study, immunofluorescence staining indicated that Ki-67 expression was lower in the SPC-A1/Thoc1 cell tumors, and that the protein localized on the nuclear membrane. These data suggest that Thoc1-mediated inhibition of tumor growth may involve a decrease in the in vivo expression of Ki-67.

In summary, our study, investigating the role of Thoc1 in lung cancer cell growth, showed that this protein induces cell phase arrest at $\mathrm{G} 2 / \mathrm{M}$, accompanied by an accumulation of cell cycle-related proteins, changes in the expression level of several proteins that directly relate to cell apoptosis, and a reduction in both in vitro and in vivo cell growth. These findings provide new insights into the role of Thoc1 in lung cancer and may have important implications in the development of targeted therapies for lung cancer.

\section{Acknowledgments}

This study was supported by grants from the National Natural Science Foundation of China (no. 81071906 and 81172127) and the Priority Academic Program Development (PAPD) of Jiangsu Higher Education Institutions.

\section{References}

1. Siegel R, Naishadham D and Jemal A: Cancer statistics, 2013. CA Cancer J Clin 63: 11-30, 2013.

2. Brunagel G, Vietmeier BN, Bauer AJ, Schoen RE and Getzenberg RH: Identification of nuclear matrix protein alterations associated with human colon cancer. Cancer Res 62: 2437-2442, 2002.

3. Dey P: Chromatin pattern alteration in malignant cells: an enigma. Diagn Cytopathol 32: 25-30, 2005.

4. Zink D, Fischer AH and Nickerson JA: Nuclear structure in cancer cells. Nat Rev Cancer 4: 677-687, 2004.

5. Durfee T, Mancini MA, Jones D, Elledge SJ and Lee WH: The amino-terminal region of the retinoblastoma gene product binds a novel nuclear matrix protein that co-localizes to centers for RNA processing. J Cell Biol 127: 609-622, 1994.

6. Nickerson J: Experimental observations of a nuclear matrix. J Cell Sci 114: 463-474, 2001

7. Ruh MF, Dunn R, 2nd and Ruh TS: Interrelationships between nuclear structure and ligand-activated intracellular receptors. Crit Rev Eukaryot Gene Expr 6: 271-283, 1996.

8. Martelli AM, Bareggi R, Bortul R, Grill V, Narducci P and Zweyer M: The nuclear matrix and apoptosis. Histochem Cell Biol 108: 1-10, 1997.

9. Barboro P, Repaci E, D'Arrigo C and Balbi C: The role of nuclear matrix proteins binding to matrix attachment regions (Mars) in prostate cancer cell differentiation. PLoS One 7: e40617, 2012.

10. Getzenberg RH, Konety BR, Oeler TA, Quigley MM, Hakam A, Becich MJ and Bahnson RR: Bladder cancer-associated nuclear matrix proteins. Cancer Res 56: 1690-1694, 1996.

11. Konety BR, Nangia AK, Nguyen TS, Veitmeier BN, Dhir R, Acierno JS, Becich MJ, Hrebinko RL and Getzenberg RH: Identification of nuclear matrix protein alterations associated with renal cell carcinoma. J Urol 159: 1359-1363, 1998.

12. Getzenberg RH, Pienta KJ, Huang EY and Coffey DS: Identification of nuclear matrix proteins in the cancer and normal rat prostate. Cancer Res 51: 6514-6520, 1991.

13. Luftner D and Possinger K: Nuclear matrix proteins as biomarkers for breast cancer. Expert Rev Mol Diagn 2: 23-31, 2002.

14. Partin AW, Briggman JV, Subong EN, Szaro R, Oreper A, Wiesbrock S, Meyer J, Coffey DS and Epstein JI: Preliminary immunohistochemical characterization of a monoclonal antibody (PRO:4-216) prepared from human prostate cancer nuclear matrix proteins. Urology 50: 800-808, 1997. 
15. Guo S, Hakimi MA, Baillat D, Chen X, Farber MJ, Klein-Szanto AJ, Cooch NS, Godwin AK and Shiekhattar R: Linking transcriptional elongation and messenger RNA export to metastatic breast cancers. Cancer Res 65: 3011-3016, 2005.

16. Yang J, Li Y, Khoury T, Alrawi S, Goodrich DW and Tan D: Relationships of $\mathrm{hHprl} / \mathrm{p} 84 / \mathrm{Thoc} 1$ expression to clinicopathologic characteristics and prognosis in non-small cell lung cancer. Ann Clin Lab Sci 38: 105-112, 2008.

17. Gasparri F, Sola F, Locatelli G and Muzio M: The death domain protein $\mathrm{p} 84 \mathrm{~N} 5$, but not the short isoform $\mathrm{p} 84 \mathrm{~N} 5 \mathrm{~s}$, is cell cycle-regulated and shuttles between the nucleus and the cytoplasm. FEBS Lett 574: 13-19, 2004.

18. Doostzadeh-Cizeron J, Yin S and Goodrich DW: Apoptosis induced by the nuclear death domain protein p84N5 is associated with caspase- 6 and NF-kappa B activation. J Biol Chem 275: 25336-25341, 2000

19. Doostzadeh-Cizeron J, Terry NH and Goodrich DW: The nuclear death domain protein p84N5 activates a G2/M cell cycle checkpoint prior to the onset of apoptosis. J Biol Chem 276: $1127-1132,2001$

20. Li Y, Wang X, Zhang $X$ and Goodrich DW: Human $\mathrm{hHpr} 1 / \mathrm{p} 84 /$ Thocl regulates transcriptional elongation and physically links RNA polymerase II and RNA processing factors. Mol Cell Biol 25: 4023-4033, 2005.

21. Tyagi AK, Singh RP, Agarwal C, Chan DC and Agarwal R Silibinin strongly synergizes human prostate carcinoma DU145 cells to doxorubicin-induced growth inhibition, G2-M arrest, and apoptosis. Clin Cancer Res 8: 3512-3519, 2002.

22. Singh RP, Dhanalakshmi S and Agarwal R: Phytochemicals as cell cycle modulators - a less toxic approach in halting human cancers. Cell Cycle 1: 156-161, 2002.

23. Nahta R and Esteva FJ: Bcl-2 antisense oligonucleotides: a potential novel strategy for the treatment of breast cancer. Semin Oncol 30: 143-149, 2003.
24. Ghobrial IM, Witzig TE and Adjei AA: Targeting apoptosis pathways in cancer therapy. CA Cancer J Clin 55: 178-194, 2005.

25. Kymionis GD, Dimitrakakis CE, Konstadoulakis MM, Arzimanoglou I, Leandros E, Chalkiadakis G, Keramopoulos A and Michalas S: Can expression of apoptosis genes, bcl-2 and bax, predict survival and responsiveness to chemotherapy in node-negative breast cancer patients? J Surg Res 99: 161-168, 2001.

26. Fulda S and Debatin KM: Extrinsic versus intrinsic apoptosis pathways in anticancer chemotherapy. Oncogene 25: 4798-4811, 2006.

27. Endl E and Gerdes J: The Ki-67 protein: fascinating forms and an unknown function. Exp Cell Res 257: 231-237, 2000

28. Scholzen T and Gerdes J: The Ki-67 protein: from the known and the unknown. J Cell Physiol 182: 311-322, 2000.

29. Bridger JM, Kill IR and Lichter P: Association of pKi-67 with satellite DNA of the human genome in early G1 cells. Chromosome Res 6: 13-24, 1998.

30. MacCallum DE and Hall PA: The location of pKi67 in the outer dense fibrillary compartment of the nucleolus points to a role in ribosome biogenesis during the cell division cycle. J Pathol 190: $537-544,2000$

31. Ruiz C, Seibt S, Al Kuraya K, Siraj AK, Mirlacher M, Schraml P, Maurer R, Spichtin H, Torhorst J, Popovska S, et $a l$ : Tissue microarrays for comparing molecular features with proliferation activity in breast cancer. Int J Cancer 118: 21902194, 2006

32. Irigoyen MA, Garcia FV, Iturriagagoitia AC, Beroiz BI, Martinez MS and Grima FG: Molecular subtypes of breast cancer: prognostic implications and clinical and immunohistochemical characteristics. An Sist Sanit Navar 34: 219-233, 2011 (In Spanish). 